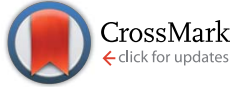

Cite this: RSC Adv., 2016, 6, 2712

Received 23rd September 2015 Accepted 21st December 2015

DOI: $10.1039 / c 5 r a 19652 c$

www.rsc.org/advances

\section{Immune compatible cystine-functionalized superparamagnetic iron oxide nanoparticles as vascular contrast agents in ultrasonography $\dagger$}

\author{
Sara Dolci, ${ }^{a}$ Valentina Domenici, ${ }^{a}$ Gianpaolo Vidili, ${ }^{b}$ Marco Orecchioni, ${ }^{c}$ \\ Pasquale Bandiera, ${ }^{d}$ Roberto Madeddu, ${ }^{d}$ Cristiano Farace, ${ }^{d}$ Massimiliano Peana, ${ }^{c}$ \\ Maria Rosaria Tiné, ${ }^{a}$ Roberto Manetti, ${ }^{b}$ Francesco Sgarrella ${ }^{c}$ \\ and Lucia Gemma Delogu*c
}

Superparamagnetic iron oxide nanoparticles (SPIONs) have been extensively investigated for many biomedical applications. A good quality functionalization that combines imaging goals with a high-level of biocompatibility remains one of the challenges for particle translation into medical practice. Here, we focus on a new functionalization of SPIONs with cystine (Cy-SPIONs). Cystine is able to make SPIONs stable and dispersible in water and in culture cell media. New insights are provided into the biological and immune effects of Cy-SPIONs with a wide variety of standard and molecular assays to evaluate cytotoxicity, cell activation, cytokine release and the expression of 84 genes related to immune responses. A good immune biocompatibility of Cy-SPIONs on primary immune cells was found. The great potential of Cy-SPIONs for further in vivo studies and as contrast agents for magnetic resonance imaging (MRI) is highlighted. In addition, we also exploited ultrasonography, since it is a safer, less expensive and common imaging technology. The good echogenic properties of Cy-SPIONs in water and in whole blood are shown, both in vitro and in a phantom vein for bloodstream simulations. Our results open up a new scenario for future applications of cystine-functionalized SPIONs as immune-compatible ultrasound and MRI contrast agents.

\section{Introduction}

Magnetic nanoparticles have attracted much interest among scientists and the general public ${ }^{1}$ as advanced nanomaterials for several types of applications, as well as for drug and gene delivery or/and imaging agents. ${ }^{2,3}$ Superparamagnetic iron oxide nanoparticles (SPIONs) have been investigated for biomedical applications such as tissue repair, immunoassays, detoxification of biological fluids, hyperthermia, drug delivery, probes, in vitro cell separation and to produce antibioticresistant biofilms. They are thus important candidate materials for new perspectives in nanomedicine. ${ }^{4}$

Since 2005 SPIONs were introduced as tracers for tomographic magnetic particle imaging modality. ${ }^{5}$ One of the major

\footnotetext{
${ }^{a}$ Department of Chemistry and Industrial Chemistry, University of Pisa, Via Moruzzi 13, 56124 Pisa, Italy

${ }^{b}$ Department of Clinical and Experimental Medicine, University of Sassari, Viale San Pietro, 07100 Sassari, Italy

${ }^{c}$ Department of Chemistry and Pharmacy, University of Sassari, Via Muroni 23, 07100 Sassari, Italy.E-mail: lgdelogu@uniss.it

${ }^{d}$ Department of Biomedical Sciences, University of Sassari, Viale San Pietro 43c, 07100 Sassari, Italy

$\dagger$ Electronic supplementary information (ESI) available: TEM images of PBMCs Cy-SPIONs treated and heat map description table. See DOI: 10.1039/c5ra19652c
}

aims of scientists in improving diagnostic technologies is to create better contrast agents and superior imaging systems, however every system has its weaknesses. ${ }^{6}$

SPIONs are excellent materials for multimodal imaging. ${ }^{7}$ One interesting modality is the use of MRI and ultrasonography (US) at the same time. US is fundamental in everyday clinical practice and many researchers are now using new nanomaterials to improve this imaging methodology which is very economical and safe. ${ }^{8-10}$ Further innovations in the development of diagnostic tools that possess the advantages of MRI and US dual-modality properties are still needed, i.e. the UStriggered release of therapeutic agents to tumor cells for the battle against cancer. ${ }^{\mathbf{1 1 - 1 3}}$

In order to achieve efficient imaging applications and loading capacity of SPIONs, one of the main challenges is to obtain nanoparticles with good hydrophilic surface coating. ${ }^{\mathbf{1 4 - 1 6}}$ To achieve this goal the functionalization is of fundamental importance for the good biocompatibility and safety of SPIONs. Thus, the first concern is to reduce both SPIONs' instability in biological media and the concentration necessary for efficient functionalization. At the same time this would minimize toxic effects and costs, while maintaining a high-resolution contrast. In a previous work, we reported a new method to increase the stability of SPIONs in biological media through the surface 
coating of SPIONs with cystine. ${ }^{17}$ Cystine acts as a precursor for proteins, antioxidant glutathione (GSH) biosynthesis, as well as maintaining physiological redox conditions inside/outside the cell. $^{18}$ We found that this new type of functionalization improved SPIONs' hydrophilicity and water stability. ${ }^{\mathbf{1 7}, 19}$ Preliminary NMR relaxation studies have also highlighted their interesting properties as Magnetic Resonance Imaging (MRI) contrast agents. However, an extensive and molecular assessment of the potential impact of SPIONs on immune cells is still lacking. Toxicity and immune compatibility are still major blocks to the use of nanomaterials in medicine..$^{20-24}$ Thus, all the applications cited above normally require intravenous administration and the first cells that come in contact with foreign substances are blood immune cells. It is therefore necessary to analyze the possible impact of SPIONs on immune cells also using a molecular approach such as gene expression analysis. Jin R. et al. ${ }^{15}$ highlighted the importance of immunological studies especially for the potential use of SPIONs in future preclinical testing, considering also that any difference in nanoparticle-conjugated moiety can lead to a different toxicological and immune impact. SPIONs have been used for MRI imaging of inflammation sites in the body, mainly looking at the monocytes/macrophage interaction and at the inflammation response in tissue..$^{25,26}$

Most studies that have analyzed the effect of SPIONs on immune cells, have only considered one type of immune cell population, such as monocytes or macrophages. ${ }^{27-31}$ Instead in this study we used total PBMCs for our analysis, which include many different cell populations, such as $\mathrm{T}$ cells, B cells, monocytes, NK cells and dendritic cells.

Our approach better simulates the normal bloodstream behavior with the interaction of different types of cells that can modulate each other's activations against foreign substances, such as nanoparticles. The ex vivo analysis also gives a better overview of the real action of Cy-SPIONs on immune cells, opening up the way for future pre-clinical application studies. To lay the foundation of our cystine functionalized SPIONs (CySPIONs) in imaging, it is also critical to assess their contrast properties. We thus decided to start from the safest imaging modality: ultrasonography.

In this paper we focus on Cy-SPIONs, which are easily dispersible in biological media. We provide new insights into the biological and immune effects of Cy-SPIONs with a standard and molecular range of assays to evaluate the cytotoxicity (ex vivo and in silico in a synthetic microvasculature network chip after US), cell activation, cytokine release and the expression of 84 genes related to the immune response. In addition, the echogenic properties of Cy-SPIONs were assessed in vitro in degassed water and ex vivo in human blood. We show how $\mathrm{Cy}$ SPIONs could be used in US as safety novel intravenous contrast agents.

\section{Experimental section}

\section{Materials}

Iron pentacarbonyl $\left(\mathrm{Fe}(\mathrm{CO})_{5}\right)$, oleic acid $\left(\mathrm{C}_{18} \mathrm{H}_{34} \mathrm{O}_{2}\right)$, dioctyl ether $\left(\mathrm{C}_{16} \mathrm{H}_{34} \mathrm{O}\right)$, trimethylamine $\mathrm{N}$-oxide $\left(\mathrm{C}_{3} \mathrm{H}_{9} \mathrm{NO}\right)$, ethanol, $\mathrm{L}^{-}$ cysteine $\left(\mathrm{C}_{3} \mathrm{H}_{7} \mathrm{NO}_{2} \mathrm{~S}\right)$ and hexane were purchased from SigmaAldrich ${ }^{\circledR}$. Toluene was distilled from the usual drying agents under nitrogen. All reactions were carried out under a nitrogen atmosphere using standard Schlenk techniques. The reaction vessels were oven-dried at $130{ }^{\circ} \mathrm{C}$ prior to use, evacuated (10$2 \mathrm{mmHg}$ ) and then filled with nitrogen.

\section{Synthesis and characterization of Cy-SPIO nanoparticles}

To obtain monodisperse, highly crystalline and nanometer-size iron oxide nanoparticles, oleate-coated SPIONs (OA-SPIONs) were prepared by following a thermal decomposition method $^{32}$ and then functionalized with cystine using a ligand exchange reaction, as described in ref. $24 . \mathrm{Fe}(\mathrm{CO})_{5}(0.66 \mathrm{~mL}$, $5 \mathrm{mmol}$ ) was added to a solution of oleic acid $(1.59 \mathrm{~mL}, 5 \mathrm{mmol})$ in dioctyl ether $(50 \mathrm{~mL})$ at $373 \mathrm{~K}$, under nitrogen atmosphere. The mixture was heated to reflux $(559 \mathrm{~K})$ for 1 hour. After cooling to room temperature, anhydrous trimethylamine $\mathrm{N}$ oxide $(376 \mathrm{mg}, 5 \mathrm{mmol}$ ) was added and the mixture heated again (to $413 \mathrm{~K}$ for $2 \mathrm{~h}$ and then to reflux for $1 \mathrm{~h}$ ). Ethanol was used to precipitate the resultant OA-SPIONs, which were separated by centrifugation and dried in vacuo $\left(1.0 \times 10^{-3}\right.$ Torr $)$.

Cystine coated SPIONs (Cy-SPION) were prepared by dissolving OA-SPIONs (506.4 mg, iron content $30.3 \%(\mathrm{w} / \mathrm{w})$ ) in $80 \mathrm{~mL}$ of toluene and adding an excess of L-cysteine $(1.485 \mathrm{~g}$, $12.25 \mathrm{mmol}$ ) under nitrogen atmosphere. The resulting brown mixture was heated to reflux $(383 \mathrm{~K})$ for about $4 \mathrm{~h}$, up to the precipitation of a brown solid to the bottom of the flask that produced a colorless solution. The solid was washed with hexane, collected by centrifugation and dried in vacuo $(1.0 \times$ $10^{-3}$ Torr). The solid was then washed with water to remove the free L-cysteine and dried with a vacuum pump. During the exchange reaction, the oxidation of cysteine to cystine takes place, promoted by $\mathrm{Fe}_{2} \mathrm{O}_{3},{ }^{17}$ until complete replacement of the oleic acid by the in situ generated cystine.

The iron content of SPIONs was determined by the spectrophotometric method. ${ }^{\mathbf{1 7 , 1 9}}$ The SPION size and morphology were determined by analyzing TEM images obtained with a Philips CM 12 operating at $100 \mathrm{kV}$. Samples were prepared by placing one drop of a solution of Cy-SPION in water on the specimen grid and allowing the solvent to evaporate. The SPION dimensions were analysed with ImageJ. The surface functionalization of Cy-SPIONs was characterized by several complementary techniques. $^{\mathbf{1 7 , 1 9}}$

\section{MRI phantom analysis of Cy-SPION dispersions}

Additional experiments were carried out to investigate the stability of water Cy-SPION dispersions and their MRI potentialities. In particular, in vitro ${ }^{1} \mathrm{H}$ NMR relaxation rates measurements were performed on aqueous Cy-SPION dispersions containing increasing iron concentrations using the 7 Tesla 950-MR scanner GE Healthcare machine.

Approximately $13 \mathrm{mg}$ of Cy-SPIONs were introduced in a vial and $1 \mathrm{~mL}$ of deionized water were added. After 10 minutes of sonication with a BRANSONIC 220 water bath sonicator, the vial was centrifuged for 5 minutes at $3500 \mathrm{rpm}$ to remove nanoparticles in the mixture. The solution was then diluted in 
various ratios in order to obtain Cy-SPION aqueous dispersions at various concentrations. NMR glass tubes containing CySPION dispersions with [Fe] equal to $0.320,0.213,0.160$ and $0.106 \mathrm{mM}$ were placed in an agar phantom and the proton NMR relaxation times, $T_{1}$ and $T_{2}^{*}$, were recorded using standard inversion recovery (IR) and spin echo (SE) sequences, respectively.

\section{Ultrasound imaging}

Technos MPX (Esoate) was used for all ultrasonography experiments. The analyses were recorded at $14 \mathrm{MHz}$; the instrument was set in conventional US modality (B mode), depth $31 \mathrm{~mm}$, gain $170,-1.3 \mathrm{~dB}$, and mechanical index $=1$. The US signal was calculated using Adobe Photoshop CS5 (Adobe Systems). US signal is reported in 8 bit gray scale intensity from 0 to 255 shades of gray. For US images on degassed water, the areas of interest were selected. A comparison of samples was performed on the same areas with 29205 analyzed pixels. Experiments were done in triplicate.

\section{Cell culture maintenance}

Jurkat cells ( $\mathrm{T}$ cell line) and peripheral blood mononuclear cells (PBMCs) were cultured in RPMI 1640 medium containing 1\% antibiotic-antimicotic mixture and $10 \%$ heat-inactivated fetal bovine serum (FBS) (Invitrogen) in an incubator at $37^{\circ} \mathrm{C}$ in a $5 \%$ $\mathrm{CO}_{2}$. Human PBMCs were obtained from blood samples from healthy male donors (25-50 years old) using a standard FicollPaque (GE Healthcare) separation. All the donors provided written informed consent. The study was reviewed and approved by the ethics committee of the University of Sassari (Italy).

\section{Cy-SPION viability and activation on immune cells}

For the viability assay, PBMCs were transferred to a 24 -well plate and treated for $24 \mathrm{~h}$ in triplicate with $50,100,200 \mu \mathrm{g} \mathrm{mL} \mathrm{m}^{-1}$ of CySPION or left untreated. Cells were treated with EtOH $70 \%$ as a positive control and then washed in cold PBS before the staining reaction. After incubation, cells were harvested, washed in cold PBS and re-suspended in $1 \mathrm{~mL}$ of PBS at $1 \times 10^{6}$ cells per mL. Viability was assessed by the LIVE/DEAD® Fixable Dead Cell Stain Kit (Invitrogen), which uses an amine-reactive fluorescent dye, cells with compromised membranes (late apoptotic and necrotic). The dye reacts with free amines both inside the cell and on the cell surface, yielding intense fluorescent staining. In viable cells, the dye reactivity is restricted to the cell surface amines, resulting in less intense fluorescence.

To detect cells undergoing apoptosis and necrosis, AnnexinV FITC and propidium iodide staining were used (Invitrogen). Cells were analysed by flow cytometry (FACS Calibur BDBioscience). To identify $\mathrm{T}$ cells and specifically CD8+ and CD4+ $\mathrm{T}$ cell populations, the populations were isolated using specific antibodies: CD3 for the entire T cell gating, CD8 and CD4 for cytotoxic $\mathrm{T}$ cells and $\mathrm{T}$ helper cells, respectively. To assess the cell activation, specific antibodies were used against CD25, CD69 and CD30 cell activation markers. Al the antibodies used were purchased from BD Biosciences. Data analysis was performed by flow cytometry (FACS Calibur, BD Biosciences) using CellQuest ${ }^{\circledR}$ software (BD Biosciences).

\section{Proliferation assay}

To perform the proliferation assay, the Click-iT EdU Alexa Fluor 488 Flow Cytometry Assay Kit (Life Technologies) was used. The experiments were performed according to the manufacturer's instructions. Cells were seeded at the concentration of $1 \times 10^{6}$ cells per $\mathrm{mL}$ in 96 multi-well rounded bottom plates. PBMCs were treated with Cy-SPIONs $\left(50,100,200 \mu \mathrm{g} \mathrm{mL}{ }^{-1}\right)$ and phytohemagglutinin 2\% (PHA) and interleukin 2 (IL2) 30 $\mathrm{u} \mathrm{mL}^{-1}$ or left untreated. 5-Ethynyl-2-deoxyuridine (EdU) was added in sterile conditions $16 \mathrm{~h}$ before the analysis. After $72 \mathrm{~h}$ of incubation, cells were harvested, washed in PBS, fixed with $4 \%$ paraformaldehyde, washed in PBS $+1 \%$ BSA, permeabilized with a saponin-based reagent, and prepared for the $\mathrm{Cu}$-assisted EdU-Azide Click-iT reaction. The reaction occurs after adding $500 \mu \mathrm{L}$ of Click-iT reaction cocktail (PBS, $\mathrm{CuSO}_{4}$, fluorescent dye azide and reaction buffer additive) to each sample. Analyses were performed by flow cytometry (FACS Calibur BD Bioscience) using CellQuest ${ }^{\circledR}$ software (BD Biosciences). A total of 50000 100000 events were recorded.

\section{Idealized synthetic microvascular network (SMN) and related viability test}

The Synthetic Microvascular Networks or SMNs were purchased from SYN VIVO CFDRC Huntsville, Alabama, USA. The SMN is able to perfectly reproduce a trait of the rat microvasculature (vessels depth of $100 \mu \mathrm{m}$ ). The chip was developed using a standard photolithography process. ${ }^{33}$ The SMN was used in order to assess the potential impact of Cy-SPIONs on human primary immune cells in an in vivo like simulation under ultrasonography. Tygon tubing was inserted into the inlet/outlet ports of the device, a syringe was loaded onto a syringe pump and PBMCs with or without Cy-SPIONs $\left(200 \mu \mathrm{g} \mathrm{mL}{ }^{-1}\right)$ injected at rates flow of less than $1 \mu \mathrm{L} \mathrm{min}{ }^{-1}$. After $24 \mathrm{~h}$ of incubation at $37{ }^{\circ} \mathrm{C}$ in $5 \%$ of $\mathrm{CO}_{2}$, the device was covered with plastic paper and gel for ultrasonography, and sonication with an US probe was then performed for 10 minutes. PBMCs with or without CySPIONs were immediately extracted and cell count performed with a trypan blue solution (4\%, Sigma Aldrich) under inverted microscopy (Nikon Instruments Inc.).

\section{Immune cell gene expression analysis}

Total RNA was extracted from Jurkat cells after incubation with SPIONs $200 \mu \mathrm{g} \mathrm{mL}^{-1}$. RNA purification was performed with TriZol Reagent (TriZol, Invitrogen, Carlsbad, CA, USA). After extraction, cDNA synthesis was performed using a SuperScript ${ }^{\circledR}$ II reverse transcriptase (Invitrogen) following the manufacturer's instruction. Comparison of the relative expression levels of 84 immune response genes was performed with a RT2 Profiler PCR Array (PAHS-052ZD, Superarray Bioscience Corporation, Frederick, MD), (instrument CFX96 Bio-Rad). Data were analyzed by the comparative threshold cycle (CT) method. The relative quantification of the gene expression using the $2^{-\Delta \Delta C_{t}}$ method correlated with the absolute gene quantification 
obtained using a standard curve. Data were analyzed with RT2 profiler PCR array data analysis software (http:// www.superarray.com/pcrarraydataanalysis.php). Untreated cells were compared to Cy-SPIONs treated samples. Experiments were performed in triplicate.

\section{Results and discussion}

\section{Synthesis and characterization of Cy-SPIONs}

In this work we studied the bio-immune impact and properties in ultrasound imaging of SPIONs with a new type of functionalization, using cystine. Cystine has a fundamental biological role as a component of antioxidant glutathione (GSH), and also for the maintenance of physiological redox conditions inside and outside the cell. The cystine receptor is also present in many cells of the body and is responsible for many biological processes. ${ }^{18}$

Our previous studies ${ }^{17,19}$ showed that Cy-SPIONs are stable nanoparticles and very interesting for medical applications, since their dispersion in water is quite stable. The preparation of Cy-SPIONs involves the synthesis of oleate-coated SPIONs (OA-SPION) by a thermal decomposition method ${ }^{34}$ and the subsequent functionalization by a ligand exchange reaction with L-cysteine.

Using X-ray diffraction, magnetic properties and microscopy analysis (i.e. TEM and AFM), it was possible to characterize the chemical structure of both the magnetic core and the surface coating of Cy-NPs, as previously reported. ${ }^{19}$ In particular, the ligand exchange between oleate and cysteine was fully clarified, showing that the complete oxidation of cysteine to cystine produced an external cystine-shell, which is fundamental for biomedical applications. The water stability of Cy-NP dispersion is very important and the water dispersion was confirmed to be stable for more than 7-8 h. ${ }^{19}$ Concerning the chemical-physical properties of these Cy-NPs, both spectroscopic (FT-IR) and microscopy (AFM and TEM) studies agree with the schematic picture reported in Fig. 1A. The average iron oxide core dimension of Cy-SPIONs ranges from 3.6 and $3.95 \mathrm{~nm}$, as determined independently by three methods (namely AFM, TEM and magnetic curve analysis ${ }^{17}$ ).

As an example, a TEM image of Cy-SPIONs is shown in Fig. 1B and the corresponding dimension distribution is reported in Fig. 1C. According to the analyses of five new TEM images obtained as reported in the previous section, the average diameter of these nanoparticles was $3.95 \mathrm{~nm}$ (with a standard deviation of $0.41 \mathrm{~nm})$, in agreement with previous investigations. ${ }^{17,19}$

In our previous work, ${ }^{17}$ a preliminary study of the ${ }^{1} \mathrm{H}$ NMR relaxation properties at low and high magnetic fields indicated the potential of Cy-SPION water dispersions as MRI contrast agents. At concentrations lower than $0.5 \mathrm{mM}$, we found that the spin-lattice relaxation rate $R_{1}\left(=1 / T_{1}\right)$ decreases by increasing the value of the field, while the spin-spin relaxation rate $R_{2}(=1 /$ $T_{2}$ ) has the opposite trend. This is interesting for MRI applications, since the efficiency of contrast agents for imaging applications is related to the ratio $R_{2} / R_{1}$.
A
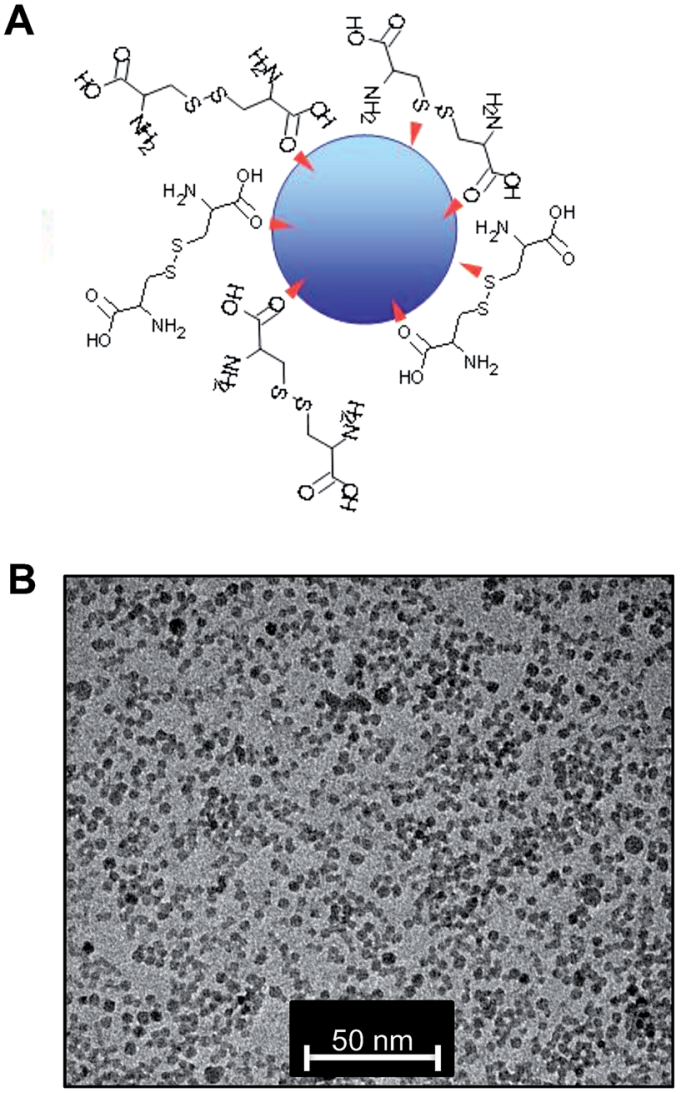

C

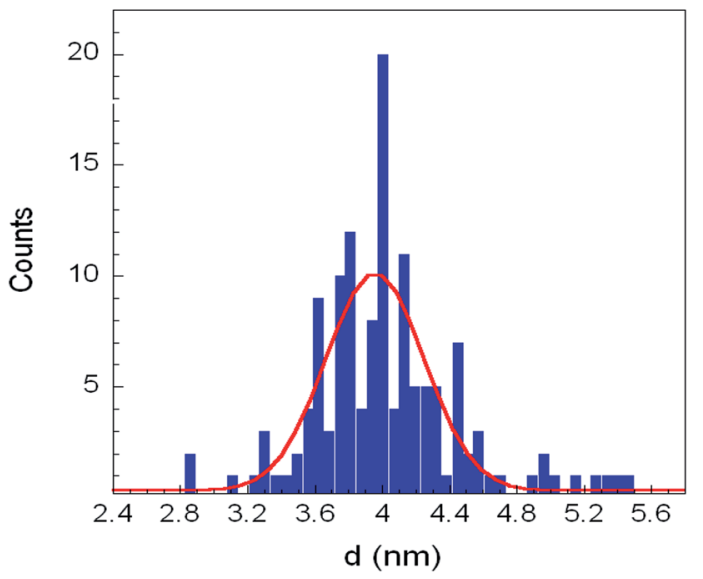

Fig. 1 Cy-SPION characterization. (A) Coating around the iron-oxide nanoparticle core. (B) TEM image of the nanoparticles showing high monodispersity and average dimension of $3.95 \mathrm{~nm}$. (C) Distribution of diameters through analysis of TEM images.

The possibility of changing this ratio by changing the magnetic field strength opens new possibilities of using our CySPIONs as negative as well as positive contrast agents. To confirm such behavior, ${ }^{17}$ we report new data acquired at 7 Tesla (corresponding to a ${ }^{1} \mathrm{H}$ Larmor frequency of $300 \mathrm{MHz}$ ) by an MRI machine. By using a phantom, prepared as described in the previous section, we collected several MRI images and calculated the relaxation rates, $R_{1}$ and $R_{2}$, of four Cy-NP dispersions with different iron concentrations (indicated in Fig. 2 as "region 
of interest", namely ROI) and one sample of pure water (ROI number 5), as a reference.

The enhancement contrast ratio (EHC) was calculated by using the following equation, in order to evaluate the contrast power:

$$
\operatorname{EHC}(\%)=\left(\frac{\left(\mathrm{SI}_{\mathrm{Cy}-\mathrm{NP}}-\mathrm{SI}_{\mathrm{water}}\right)}{\mathrm{SI}_{\text {water }}}\right) \times 100
$$

where $\mathrm{SI}_{\mathrm{Cy}-\mathrm{NP}}$ and $\mathrm{SI}_{\mathrm{water}}$ correspond to the signal intensity evaluated on the MRI image for the Cy-SPION dispersions and water reference, respectively. EHC, $R_{1}$ and $R_{2}$ of the Cy-SPIONs water dispersions are reported in Fig. 2A, while a MRI $T_{2}$ weighted image is shown in Fig. 2B.

From this investigation we can confirm that Cy-SPIONs are stable in water. In addition, the values of $\mathrm{EHC}$ and the fact that the ratio $R_{2} / R_{1}$ is in the range $20-50$ for concentrations of $\mathrm{Cy}$ SPIONs in the range $0.106-0.320 \mathrm{mM}$, indicate that these nanoparticles act as negative MRI contrast agents.

In the following sections, these nanoparticles are investigated in order to check, first, their biocompatibility and, second, their possible use as ultrasound contrast agents.

\section{Cy-SPION potential in ultrasonography imaging}

The classical application of SPIONs is as contrast agents in MRI. The recent interest in multimodal imaging has thus opened up new perspectives, indeed each imaging technique has advantages but also intrinsic limitations, in some cases low

\begin{tabular}{|l|c|c|c|c|}
\hline & {$[\mathbf{F e}](\mathbf{m M})$} & $\mathbf{R}_{\mathbf{2}}\left(\mathbf{s}^{-1}\right)$ & $\mathbf{R}_{\mathbf{1}}\left(\mathbf{s}^{-1}\right)$ & EHC \\
\hline ROI 1 & 0.320 & 20.33 & 0.42 & -69.63 \\
\hline ROI 2 & 0.213 & 14.88 & 0.43 & -59.60 \\
\hline ROI 3 & 0.160 & 11.81 & 0.40 & -50.76 \\
\hline ROI 4 & 0.106 & 8.35 & 0.39 & -35.78 \\
\hline
\end{tabular}

A

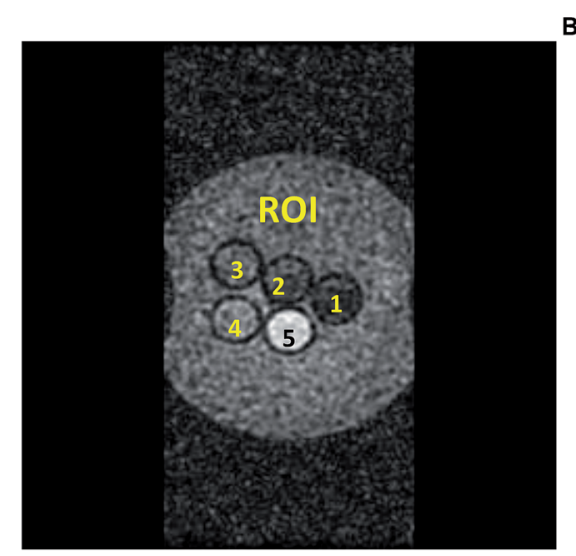

Fig. 2 Cy-SPION MRI properties. (A) In vitro relaxivity study at 7 Tesla of the four Cy-SPION dispersions. [Fe], relaxation rates $R_{1}$ and $R_{2}$, enhancement contrast ratio $(E H C)$ are reported. (B) Image of the phantom prepared with five NMR tubes with different iron contents. $\mathrm{ROI}$ number 5 corresponds to water, and is used in order to highlight the contrast effect of Cy-NPs. The MRI $T_{2}$-weighted image was obtained with an echo time of $100 \mathrm{~ms}$ and a repetition time of $2500 \mathrm{~ms}$. sensitivity, in others low spatial resolutions. ${ }^{35}$ Many groups have reported the use of SPIONs encapsulated into other particles such as microbubbles, vesicles or liposome for a bimodal imaging using MRI and US. ${ }^{36-40}$ Microbubbles are the most commonly used US contrast agents for medical applications, thanks to their highly echogenic in vivo properties. ${ }^{\mathbf{4 1}}$ The presence of SPIO nanoparticles in the bubble shell can alter the surface tension of bubbles, boosting the acoustic impedance and enhancing the detectable backscatter. Yang F. et al., for example, used SPIONs conjugated microbubbles improving their capabilities in US imaging and also, thanks to SPIONs, producing a good MRI contrast. ${ }^{37}$

The size of the most common microbubble-based US contrast agent $(1-8 \mu \mathrm{m})$ renders them as merely intravascular flow tracers and the SPIONs encapsulated in microbubbles or vesicles reached these dimensions. In contrast, the chemicophysical characteristics of SPIONs (i.e., $4 \mathrm{~nm}$ in diameter in the present study) make them potentially capable of extravasating and reaching a tumor region, which can exhibit a vascular pore size up to $780 \mathrm{~nm} . .^{42}$ The small size of SPIONs means that they can cross endothelial barriers and, as targetable materials, can reach a tumor region, acting at the same time as vehicles for therapeutic agents. ${ }^{32}$

To the best of our knowledge few studies have tested the US ability of SPIONs without any coating. For example, Mehrmohammadi M. et al. successfully used SPION (Feridex) for magneto-motive US imaging. However, they did not find a significant US signal from the free SPIONs in a tissue phantom, and they stated that SPIONs are not useful US contrast agents due to their weak reflectivity. ${ }^{43}$ We are aware of the fact that the modification of SPIONs with other molecules or particles may change their contrast properties. ${ }^{40}$

In order to investigate our uncoated Cy-SPIONs as potential ultrasound contrast agents, after having assessed the uptake and ruled out the possible cytotoxic of our nanoparticles at different concentrations, we assessed the echogenic property of Cy-SPIONs in dose responses at 50, 100 and $200 \mu \mathrm{g} \mathrm{mL}{ }^{-1}$ in degassed water. To avoid the possible bubble-formation after injection of Cy-SPION solution we carefully suspend the CySPIONs in degassed water for all the experiments. Fig. 3A shows visible and well-dispersed nanoparticles under ultrasonography. The white area visible in the US image suggests the high echogenicity of Cy-SPIONs. Interestingly, the US signal of dispersed Cy-SPIONs was three times more intense than same degassed plain water used as a negative control (11.0 vs. 43.0, respectively; $P<0.05$ ) (Fig. 3B).

In view of the results obtained from the experiments in water, we tested the echogenic propriety of Cy-SPIONs on whole blood. Intriguingly, the red arrows in the US image (Fig. 3C) indicate a visible and strong US signal of Cy-SPION nanoparticles well dispersed in whole blood.

To confirm these data, we performed an experiment with a phantom vein and human blood to simulate the bloodstream conditions (Fig. 3D). The brightness of Cy-SPIONs after injection in the phantom vein under ultrasonography was detected (Fig. 3D). These experiments proved that Cy-SPIONs were also perfectly visible in a complex fluid such as blood that per se has 

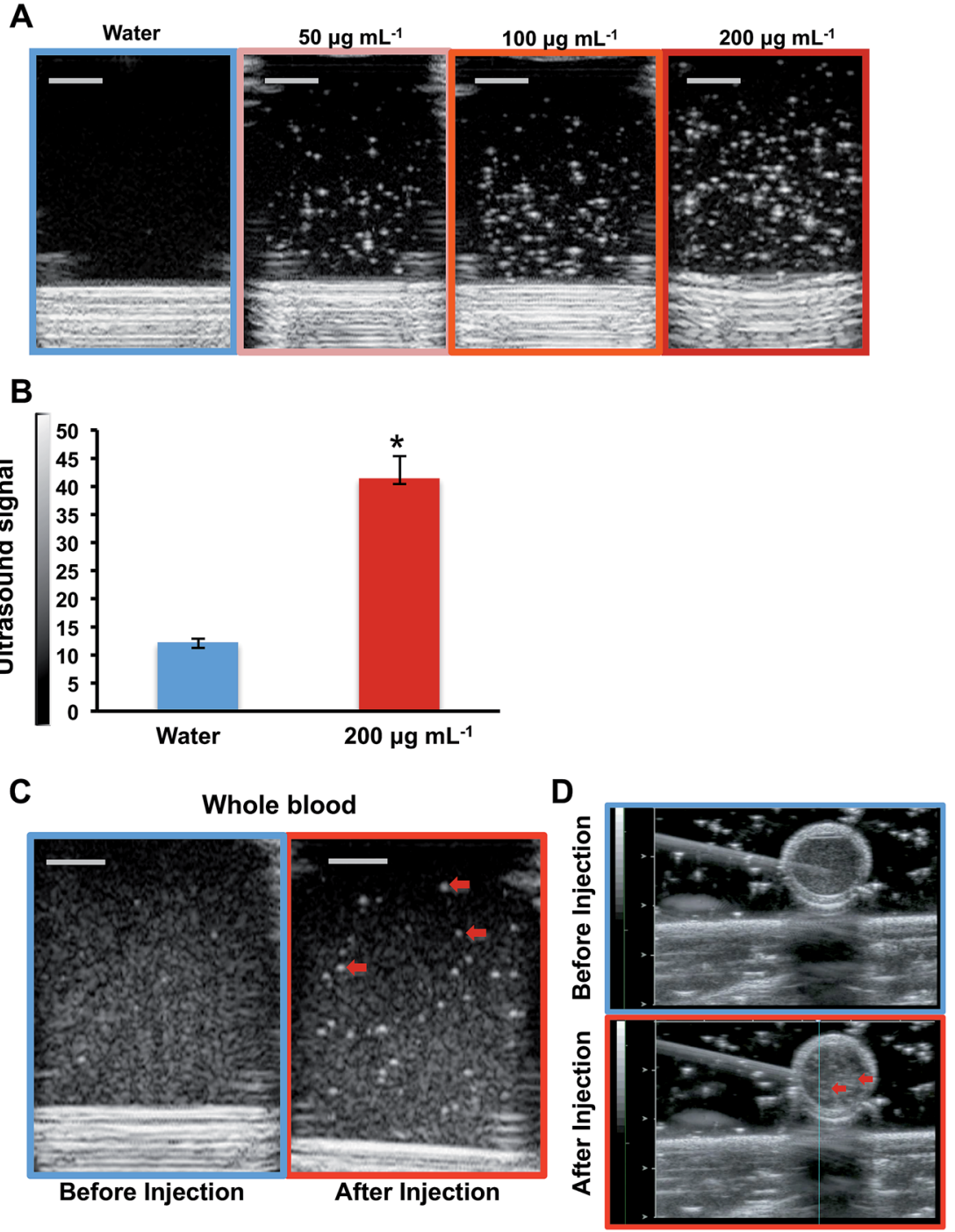

Fig. 3 Ultrasonography of Cy-SPION in water and whole blood. (A) Degassed water alone (left side) or with Cy-SPION (50, 100 and $200 \mu \mathrm{g} \mathrm{mL} \mathrm{m}^{-1}$ ) (right side) under ultrasound probe sonication in two plate wells (diameter $6.4 \mathrm{~mm}$ ). (B) Calculation of the ultrasound signal of (A) (water and 200 $\mu \mathrm{g} \mathrm{mL}^{-1}$ ) (analyzed pixels $=29$ 205). The ultrasound signal is reported in 8 bit gray scale intensity from 0 to 255 shades of gray. Signal intensity was calculated on measurements of three investigations. Degassed water was used as a negative control. ${ }^{*} p$ values $=0.05$. (C) Whole blood before and after injection with Cy-SPION (200 $\mathrm{g} \mathrm{mL}^{-1}$ ) under ultrasonography (scale bar $2.5 \mathrm{~mm}$ ). Red arrows highlight the particle signals. (D) Detection of Cy-SPION in a fresh whole blood filled vein phantom. A vein phantom was built specifically to assess the echogenic properties of Cy-SPION in whole blood from healthy donors. The phantom was constituted of non-toxic, non-hemolytic, and non-pyrogenic natural rubber medical tubing with no absorption/adhesion properties. Vein phantom showed a diameter of $0.5 \mathrm{~cm}$. The vein phantom was filled with fresh extracted human whole blood $\left(37^{\circ} \mathrm{C}\right.$ in heparin). As visible at the lower picture, a solution of Cy-SPION (100 $\mu \mathrm{L}$ at $200 \mu \mathrm{g} \mathrm{mL}{ }^{-1}$ ) was injected with a syringe; particles are clearly visible in the blood showing hyperechogenic spots (red arrow); ultrasound images were recorded at $14.0 \mathrm{MHz}$ in tissue harmonic imaging (THI) modality.

a high background signal compared to water. Our data are not in agreement with the weak reflectivity of SPIONs found by Mehrmohammadi M. et al. The higher US signal that we found with our uncoated Cy-SPIONs could be due to the different functionalization compared to Feridex used by Mehrmohammadi $\mathrm{M}$ et $a l .{ }^{43}$ Thanks to the high dispersibility in water of our CY-SPIONs, they are able to give a strong US signal.

\section{Uptake and biocompatibility of Cy-SPIONs}

SPIONs uptake has already been reported for different cell lines. ${ }^{44}$ Here for the first time we assessed their ability to cross the membrane as cystine functionalized SPIONs in ex vivo human PBMCs from healthy donors (Fig. S1†). Cells were incubated for $24 \mathrm{~h}$ with Cy-SPIONs at high doses $\left(200 \mu \mathrm{g} \mathrm{mL} \mathrm{m}^{-1}\right)$ and analyzed by TEM. Fig. $\mathrm{S} 1 \mathrm{~A} \uparrow$ shows a representative image of the control samples, where all organelles are clearly visible and correspond to the normal functionality of cells. Fig. S1B $\dagger$ shows the presence of a large number of Cy-SPION inside the cells in the treated samples. Due to their phagocytic properties, monocytes were the cell population with the highest capacity of uptake ( $>70 \%$ of visible Cy-SPION clusters) compared to the other cell types present in PBMC populations ( $\mathrm{T}$ cells, B cells, natural killers). 
Some toxicology studies with SPIONs lacking in biofunctionalization have highlighted the possible toxicity of these nanoparticles. ${ }^{\mathbf{4 5 , 4 6}}$

To check the cell compatibility of Cy-SPIONs, we performed multiparametric flow cytometry assays looking at early and late apoptosis, necrosis, cell membrane status and proliferation on ex vivo immune cells (Fig. 4). First, we performed a live/dead staining and apoptosis and necrosis assay in dose response (50, 100, $200 \mu \mathrm{g} \mathrm{mL} \mathrm{m}^{-1}$ of Cy-SPIONs) on cells incubated for $24 \mathrm{~h}$ (Fig. 4A and B). Ethanol incubation was used as a positive control. We chose these concentrations following the work of Naqvi S et al., where the authors studied the effect of SPION concentration (from 25 to $500 \mu \mathrm{g} \mathrm{mL}{ }^{-1}$ ) on immune cells, specifically on macrophages. ${ }^{47}$ Even at high concentrations of $200 \mu \mathrm{g} \mathrm{mL} \mathrm{m}^{-1}$, Cy-SPIONs did not exert any toxicity.

Data in agreement with Yeh C. H. et al.; the authors pointed out that the Resovist (FDA approved) do not give any toxicity in macrophage also at the higher concentration used $(200 \mu \mathrm{g}$ $\left.\mathrm{mL}^{-1}\right) .{ }^{48}$ Recent studies also displayed that there was no toxicity in murine macrophages after overnight labeling with Ferumoxides (Feridex, Advanced Magnetics, USA, Endorems, Guerbet, France; dextran-coated, hydrodynamic diameter of 120-180 nm). ${ }^{49}$
Differences from the control percentage were not statistically significant, including Annexin-V staining (as shown in Fig. 4A and B). In addition, we assessed whether Cy-SPIONs impact cellular proliferation (Fig. 4C) of total PBMCs and through the specific gating of $\mathrm{T}$ cells CD4+ and CD8+. We focused on the $\mathrm{T}$ cell subpopulation since it is the most abundant on PBMCs (up to $40 \%$ ) and is the easiest one to culture ex vivo for a long time, as required for proliferation assays.

Samples were treated with phytohemagglutinin at $2 \%$ and 30 $\mathrm{u} \mathrm{mL}{ }^{-1}$ of interleukin 2 for three days to boost the proliferation in the presence of magnetic particles. Control samples were left untreated. A staining with 5-ethynyl-2'-deoxyuridine (Edu) Alexa-Fluor conjugated was performed, and Edu was incorporated into DNA during active DNA synthesis. No significant difference in treated samples compared to controls was observed. However, at $200 \mu \mathrm{g} \mathrm{mL^{-1 }}$ we found a decrease in proliferation for each cell population.

These results confirmed the lack of cytotoxicity of $\mathrm{Cy}-$ SPIONs. The bio-immune-compatibility of Cy-SPIONs found may be related to the physiological functions of cystine as a component of glutathione and therefore as protection for the cells from oxidation stress.

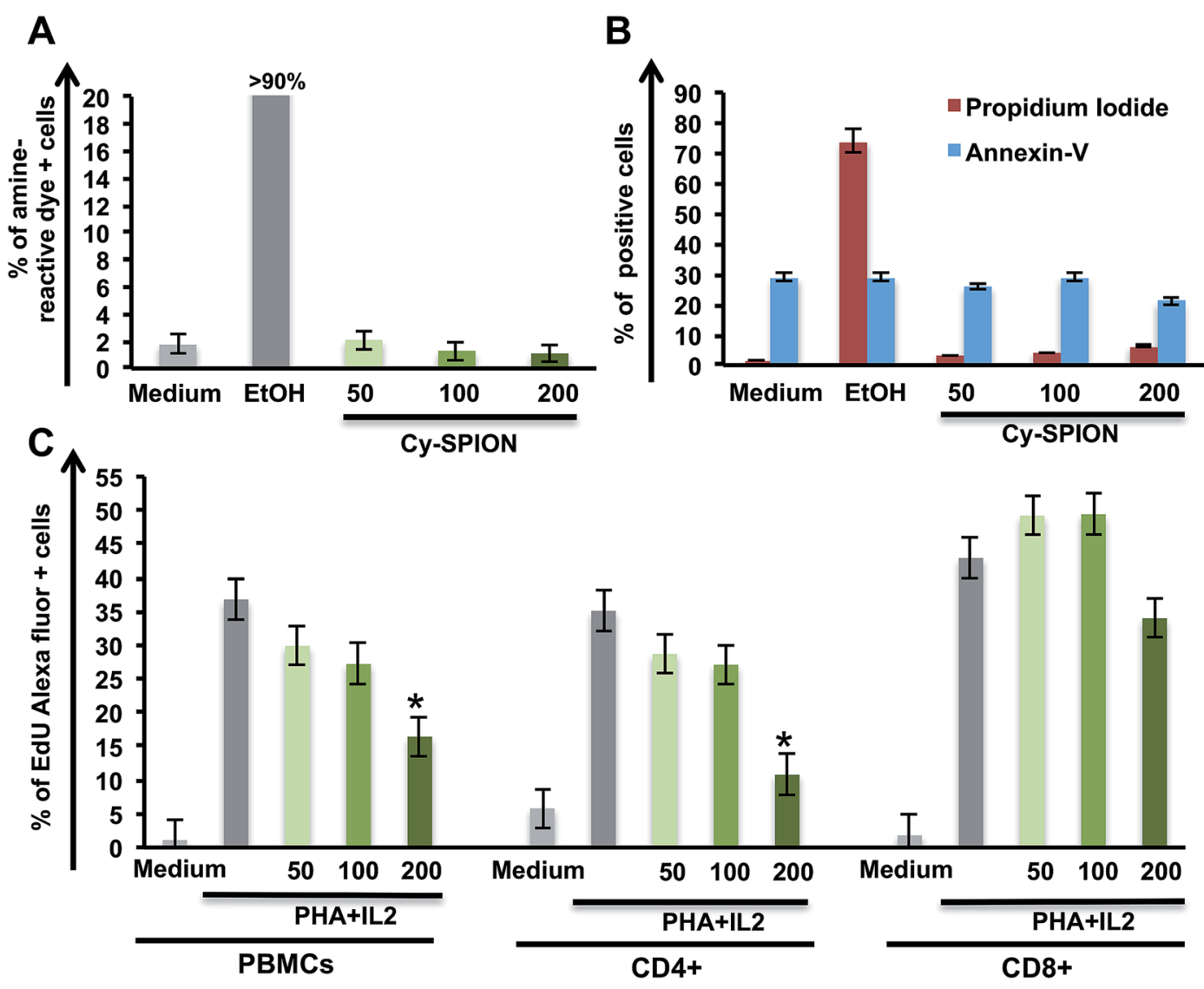

Fig. 4 Viability and proliferation assays on human primary immune cells. PBMCs were incubated with Cy-SPION at increasing doses $\left(50 \mu \mathrm{g} \mathrm{mL}^{-1}\right.$, $100 \mu \mathrm{g} \mathrm{mL}^{-1}$ and $200 \mu \mathrm{g} \mathrm{mL}^{-1}$ ) or left untreated (medium). Data were analyzed with different stainings on flow cytometry. (A) Percentage of late apoptotic and dead cells was assessed by staining with an amine-reactive dye after $24 \mathrm{~h}$ of incubation; ethanol was used as a positive control. (B) Necrosis and apoptosis were assessed using propidium iodide and Annexin V staining; ethanol was used a positive control. (C) Proliferation assay was performed on stimulated cells with phytohemagglutinin $2 \%$ (PHA) and interleukin 2 (IL2) $30 \mathrm{u} \mathrm{mL}^{-1}$ for three days. 5 -Ethynyl-2'-deoxyuridine $(\mathrm{Edu})$ is incorporated into DNA during active DNA synthesis. Edu positive cells are reported. 


\section{Biocompatibility of Cy-SPION under US into idealized} synthetic microvascular network (SMN)

Additional biocompatibility experiments were performed using a microfluidic device (SynVivo technology), which simulates the micro-vascular system of mice (Fig. 5). We used purified PBMCs treated with the higher concentration $\left(200 \mu \mathrm{g} \mathrm{mL}{ }^{-1}\right)$ of $\mathrm{Cy}-$ SPIONs; untreated PBMCs were used as a control. The cells were added to the microfluidic device and after $24 \mathrm{~h}$ of incubation with Cy-SPIONs were exposed to US for 15 minutes (the time necessary for US exams on humans) on top of the microfluidic channel, and then a viability assay with a trypan blue exclusion test was performed (Fig. 5A). Red arrows highlighted well-dispersed Cy-SPIONs inside the microchannel (Fig. 5B). No statistically significant difference in terms of percentage of dead cells between treated and control samples was found (Fig. 5C). We assume that our Cy-SPIONs are perfectly biocompatible also under US, improving their future application in in vivo applications.

\section{Cy-SPION impact in human PBMCs}

The preservation of normal immune functions is fundamental in the use of Cy-SPIONs for potential treatment or the future

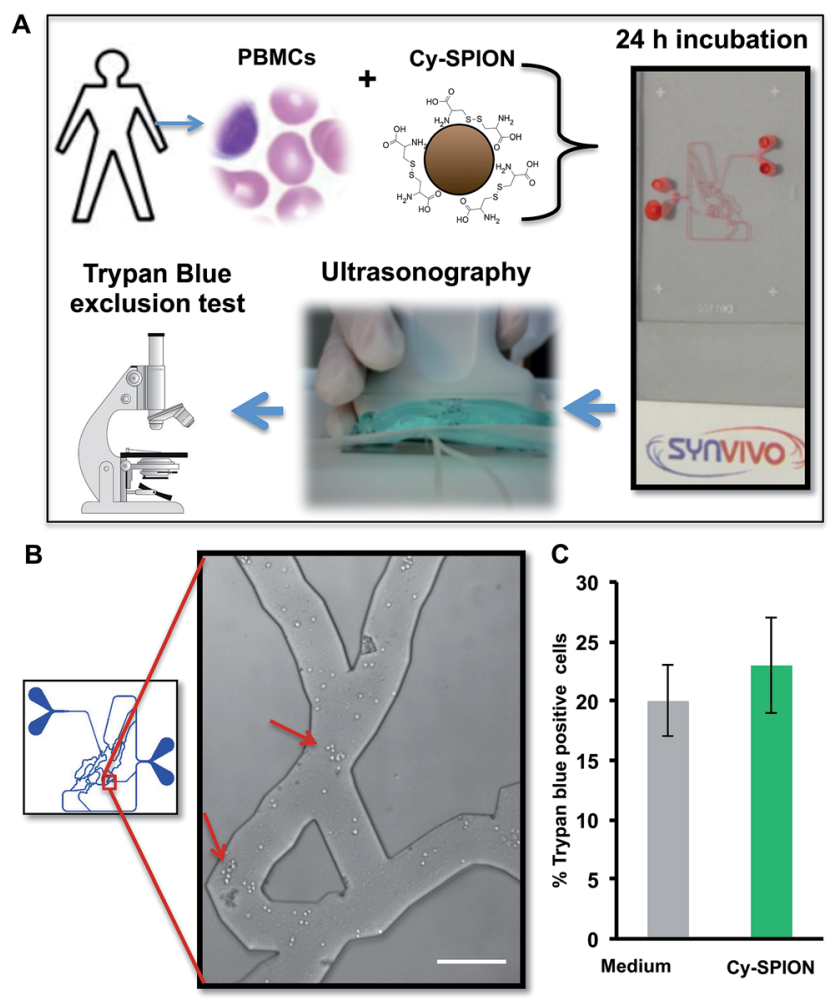

Fig. 5 In silico microvasculature assay and viability under ultrasonography. (A) PBMCs were extracted from healthy donors and treated with Cy-SPION $200 \mu \mathrm{g} \mathrm{mL}^{-1}$ or left untreated. Cells were incubated in the synthetic microvasculature network (SMN) chip for 24 h, ultrasonography was applied for 15 minutes and viability assay (trypan blue exclusion test) was performed. (B) Phase image of a $100 \times \mathrm{zoom}$ in the SMN with Cy-SPION treated cell; arrows indicate some of the live primary cells in the flow. (C) Viability after ultrasonography on medium control and Cy-SPION treated primary cells (scale bar $500 \mu \mathrm{m}$ ). diagnosis of any disease. The analysis of activation reveals the functionality of immune cells. We thus investigated the expression of the activation-related surface molecules: (i) CD69, a member of the C-type lectin superfamily (Leu-23), one of the earliest cell surface antigens expressed by immune cells following activation; (ii) CD25 (alpha chain of the IL-2 receptor), a late activation antigen; and (iii) CD30, a cell membrane protein of the tumor necrosis factor receptor family. Due to their well-known activation properties, concanavalin A (Con A) and lipopolysaccharide (LPS), were used as a positive control. Fig. 6A shows the percentage of CD25+ cells after incubation with different concentrations of Cy-SPIONs, highlighting the total comparability of treated samples with controls. We also found (Fig. 6A) the same results for the CD69 and CD30 expression markers. The total absence of activation after particle incubation is also reported. As stated by Mahmoudi M. et al. there is little direct evidence on the induction of inflammatory pathways and cytokines by engineered SPIONs (both uncoated and coated) in vivo and in vitro. ${ }^{45}$

To fill this gap in the literature we studied the secretion of a wide variety of cytokines after incubation with $200 \mu \mathrm{g} \mathrm{mL}$ Cy-SPIONs in cells. In our analysis we examined four primary cytokines: TNF $\alpha$, IL10, IL6 and IL1 $\beta$ (Fig. 6B) as they are among the most important cytokines secreted from PBMCs. Multiplex ELISA assay was used for the detection.

Interestingly, we found a Cy-SPION dose-dependent increase of TNF $\alpha$, IL10 and IL6 ( $p$-value $<0.05$ ). The cytokines found expressed such as IL6 and TNF $\alpha$ are normally secreted by monocytes/macrophages and their action is normally directed on the activation of the acute inflammation process. ${ }^{50}$ IL10 is a cytokine mainly secreted by activated macrophages that through a negative feedback directly control and decrease the immune response. ${ }^{51}$ This action, as previously proved by many research groups, ${ }^{52-55}$ could be the possible consequence of the uptake of Cy-SPIONs by monocytes shown in Fig. S1. $\dagger$

Thus, studies conducted in vitro on the effect of SPIONs on macrophage functions have revealed modifications in cellular behaviors as well as in the modulated cytokine expressions. ${ }^{56,57}$ For instance, Hsiao J. K. et al. studied the response of clinicallyused SPION ferucarbotran (Resovist) loading upon macrophage and found that high doses of SPIONs induced the secretion of TNF- $\alpha$ and resulted in cellular activation through the production of nitric oxide. ${ }^{57}$ Also in the study of Yeh C. H. et al. the cytokine secretion analysis indicated that Resovist could elicit the production of pro-inflammatory cytokines such as TNF- $\alpha$, IL-1 $\beta$ and IL-6, but their levels were much lower than those with lipopolysaccharide (LPS) stimulation. $^{48}$ We found similar results with our Cy-SPION compared to other already approved SPIONs for MRI imaging evidencing no significant toxicity on immune cells. ${ }^{58,59}$

The uptake of SPIONs by phagocytic monocytes and macrophages provides a valuable in vivo tool by which imaging techniques can be used to monitor the involvement of macrophages in inflammatory processes such as multiple sclerosis, traumatic nerve injury, stroke, brain tumors, and vulnerable plaques in carotid artery. 
A
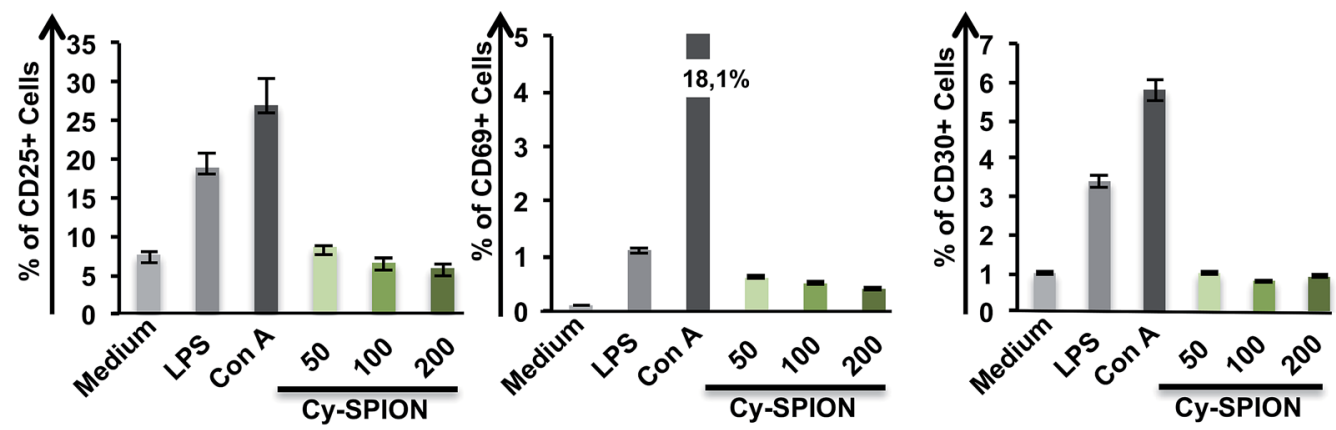

B

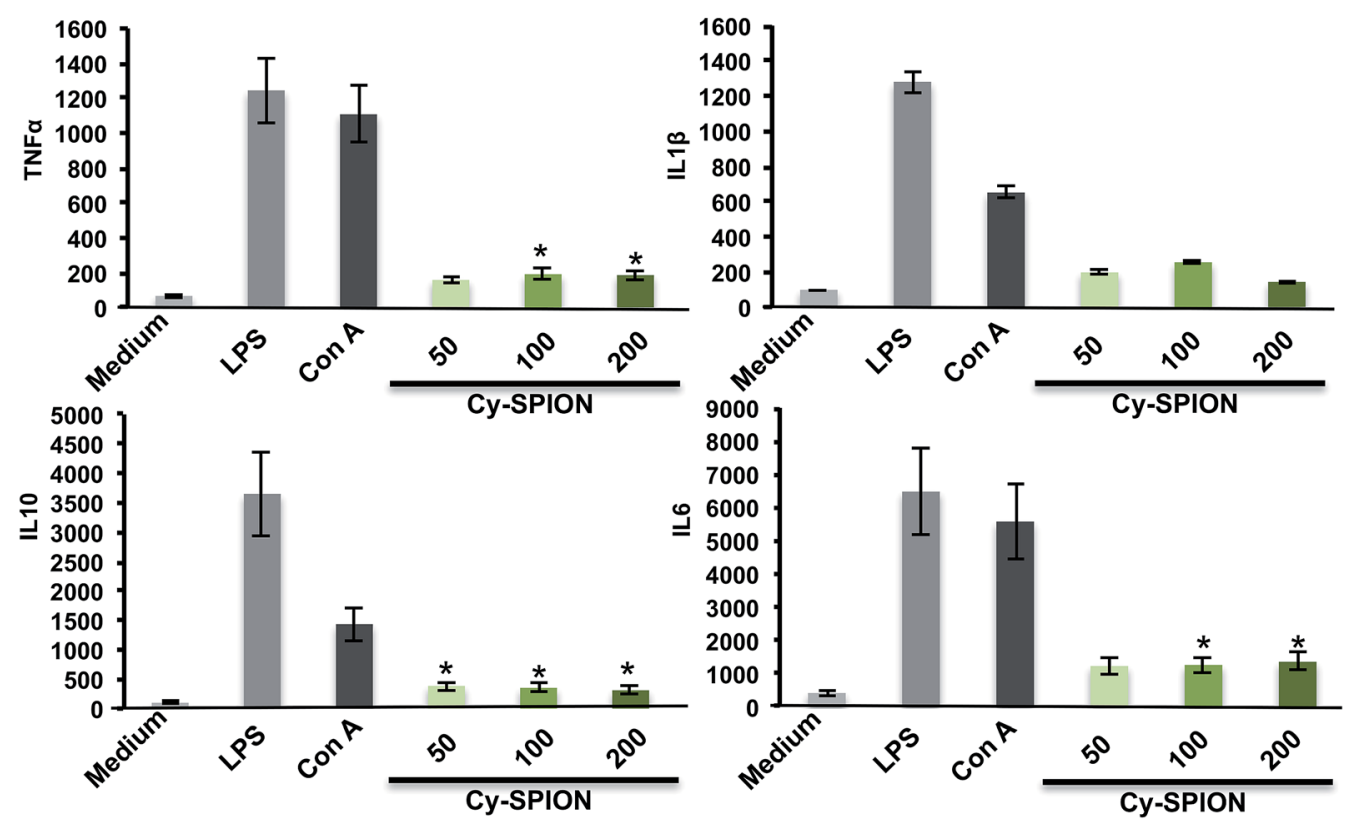

Fig. 6 Activation markers analysis and cytokines secretion assay. PBMCs were treated with Cy-SPION (50, 100 and $\left.200 \mu \mathrm{g} \mathrm{mL}{ }^{-1}\right)$ or left untreated (medium) for $24 \mathrm{~h}$. Concanavalin A (ConA, $10 \mu \mathrm{g} \mathrm{mL}^{-1}$ ) and lipopolysaccharides (LPS $2 \mu \mathrm{g} \mathrm{mL}{ }^{-1}$ ) were used as positive controls. (A) CD25, CD69 and CD30 cell surface activation markers were analyzed by flow cytometry. (B) Cytokine secretion was assessed by multiplex ELISA, values are expressed in $\mathrm{pg} \mathrm{mL}^{-1}\left({ }^{*} p\right.$ value $\left.<0.05\right)$.

Our data are in accordance with findings on commercial clinically approved SPIONs to be used as SPION-based MRI contrast agents such as Resovist, Feridex and Combidex, which are coated with dextran, other carbohydrates or citratestabilized particles. SPIONs with other functionalizations (polymers, metals, silica) are in the development phase. ${ }^{52}$

To better understand all aspects of Cy-SPIONs interaction with immune cells, an extensive genome study with an RT2 Profiler PCR Array testing was performed, studying the expression of 84 key genes on immune responses (Fig. 7). For a clear picture of gene expression, we focused on a well established $\mathrm{T}$ cell line (Jurkat) for two critical reasons: (i) it is a good model particularly for the adaptive the immune-cell response; (ii) $\mathrm{T}$ cells are the most abundant population in the blood flow, therefore their reactions can give a wide picture on SPIONs impact.

The heatmap (Fig. 7A) shows 84 genes displayed for fold change variations in comparison to the medium control and colored by their standardized expression value $($ red $=$ high expression; green $=$ low expression). The induction of TNF expression found was in perfect agreement with the cytokine data. The other genes modulated with a fold change higher than 2 were: B2M, MAPK1, TLR2, IRAK1, TYK2, NLRLP3 and HLA-A (Fig. S2 $\dagger$ ). The up-regulation of the toll-like receptor 2 (TLR2) in $\mathrm{T}$ cells led us to hypothesize that Cy-SPIONs come in contact with immune cells through a toll-like receptor. This interaction may also be responsible for the up-regulation of genes such as MAPK1, TYK2 and IRAK1, which are normally implicated in signal transduction. MAPK/ERK pathways are responsible for many functions such as cell growth and proliferations. TYK2 and IRAK1 also encode for kinases that are responsible for interferon and IL1 secretion. These data were confirmed in the scatter plot (Fig. 7B); all genes were shown in accordance to fold regulation. Only two, NLRP3 and HLA-A, were up-regulated with a fold regulation greater than 4 . Fig. $7 \mathrm{C}$ reports the up-regulated genes. The modulated genes found are not implicated with a significant modification in cell functionality, indeed the few 
A
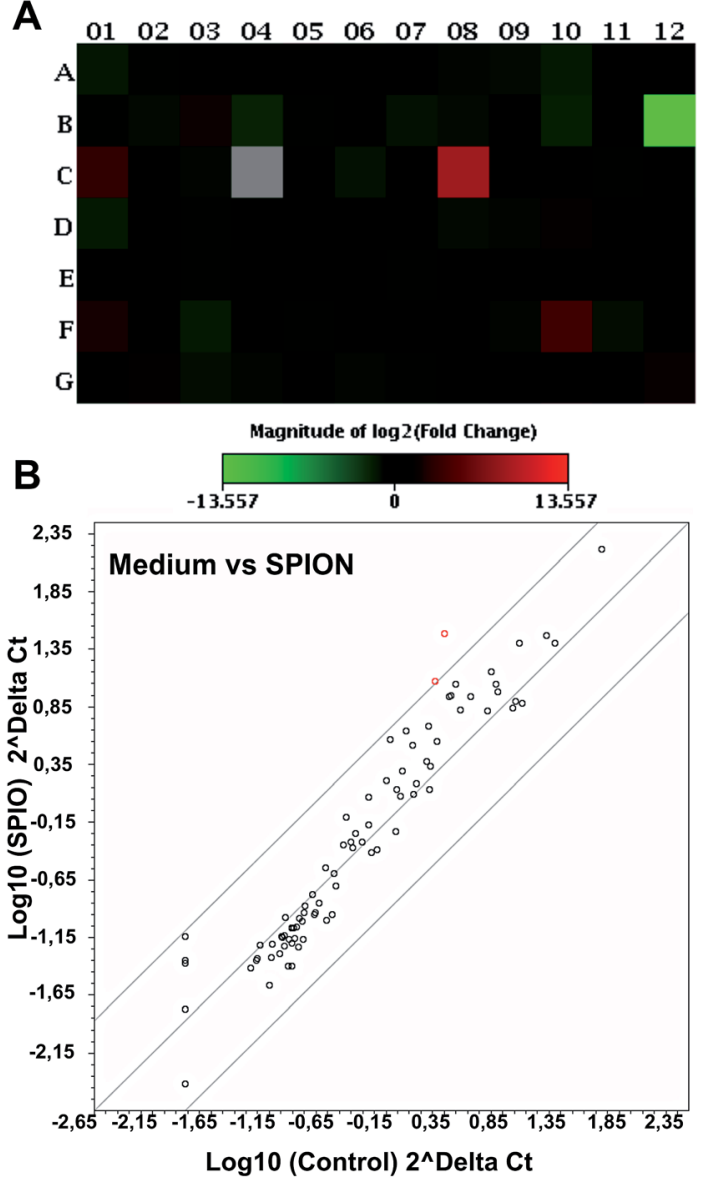

C

\begin{tabular}{|l|r|}
\hline \multicolumn{1}{|c|}{ Genes } \\
\hline B2M & 2,2141 \\
\hline TNF & 2,3302 \\
\hline MAPK1 & 2,3651 \\
\hline TLR2 & 2,6909 \\
\hline IRAK1 & 2,7644 \\
\hline TYK2 & 3,1924 \\
\hline NLRP3 & 4,2372 \\
\hline HLA-A & 9,0533 \\
\hline
\end{tabular}

Fig. 7 Immune gene expression array. T cells were incubated with CySPION $\left(200 \mu \mathrm{g} \mathrm{mL}^{-1}\right)$ for $24 \mathrm{~h}$ or left untreated. The expression of 84 immune response related genes was evaluated. (A) Heatmap CySPION treated sample versus control medium. Genes are displayed for fold change variations versus medium control and colored by their standardized expression value (red $=$ high expression, green $=$ low expression) (for gene names see Fig. S2 †). (B) Scatter plot. Genes upregulated with fold regulation $>4$ are shown in red circles. Unaffected genes are in black. (C) Modulated genes versus control with a fold change $>2$.

genes up-regulated and also the activation markers analysis did not show any cell-activation response.

\section{Conclusions}

To conclude, in this work we give new insight into the use of cystine functionalized SPIONs in imaging, not only for MRI but also for ultrasonography due to their echogenic properties in water and blood, as shown in the present study. Intriguingly the small size of our Cy-SPIONs make them able to cross endothelial barriers and, as targetable materials, to potentially reach a tumor region, acting at the same time as vehicles for therapeutic agents. The potentiality of our Cy-SPIONs to extravasate and localize in a tumoral region highlight that Cy-SPIONs could be successfully exploited for theranostic applications. Moreover our data clearly point out the good immune and biocompatibility of Cy-SPION, with absence of activation stimuli on treated PBMCs.

These findings make Cy-SPIONs perfect materials for new in vivo dual mode imaging studies where the preferential route of administration is by intravenous injections.

\section{Acknowledgements}

We thank the staff of CFD Research Corporation (Huntsville, Alabama, USA) for their technical help. The authors would also like to thank Prof. Maja Remskar for the TEM images, and Dr Michela Tosetti for giving us access to the IMAGO 7 Foundation equipment for MRI preliminary investigations. V. Domenici and M. R. Tinè thank MIUR for the project entitled "Nanoscale functional organization of (bio)molecules and hybrids for targeted application in sensing, medicine and biotechnology", PRIN 2010-2011, No. 2010C4R8M8. This work was also partly supported by the Fondazione Banco di Sardegna (grant No. 2013.1308, 2014.6035 to L. G. D.), the Sardinia Region (grant No. CRP-59720 to L. G. D.) and the Gianfranco del Prete Association "The future: medicine, biology and nanotechnology Award" to L. G. D.

\section{References}

1 G. Sechi, D. Bedognetti, F. Sgarrella, L. van Eperen, F. M. Marincola, A. Bianco and L. G. Delogu, Nanomedicine, 2014, 9, 1475-1486.

2 C. Wu, F. Gong, P. Pang, M. Shen, K. Zhu, D. Cheng, Z. Liu and H. Shan, PLoS One, 2013, 8, e66416.

3 P. Pang, C. Wu, M. Shen, F. Gong, K. Zhu, Z. Jiang, S. Guan, H. Shan and X. Shuai, PLoS One, 2013, 8, e76612.

4 A. K. Gupta and M. Gupta, Biomaterials, 2005, 26, 3995-4021. 5 B. Gleich and J. Weizenecker, Nature, 2005, 435, 1214-1217. 6 S. Lee and X. Chen, Mol. Imaging, 2009, 8, 87-100.

7 F. Liu, S. Laurent, H. Fattahi, L. Vander Elst and R. N. Muller, Nanomedicine, 2011, 6, 519-528.

8 S. G. Zheng, H. X. Xu and H. R. Chen, World J. Radiol., 2013, 5, 468-471.

9 M. Postema and O. H. Gilja, World J. Gastroenterol., 2011, 17, 28-41.

10 L. G. Delogu, G. Vidili, E. Venturelli, C. Menard-Moyon, M. A. Zoroddu, G. Pilo, P. Nicolussi, C. Ligios, D. Bedognetti, F. Sgarrella, R. Manetti and A. Bianco, Proc. Natl. Acad. Sci. U. S. A., 2012, 109, 16612-16617.

11 F. M. Kievit, Z. R. Stephen, O. Veiseh, H. Arami, T. Wang, V. P. Lai, J. O. Park, R. G. Ellenbogen, M. L. Disis and M. Zhang, ACS Nano, 2012, 6, 2591-2601. 
12 Y. Song, Z. Huang, J. Xu, D. Ren, Y. Wang, X. Zheng, Y. Shen, L. Wang, H. Gao, J. Hou, Z. Pang, J. Qian and J. Ge, Biomaterials, 2014, 35, 2961-2970.

13 M. K. Yu, D. Kim, I. H. Lee, J. S. So, Y. Y. Jeong and S. Jon, Small, 2011, 7, 2241-2249.

14 B. Basly, G. Popa, S. Fleutot, B. P. Pichon, A. Garofalo, C. Ghobril, C. Billotey, A. Berniard, P. Bonazza, H. Martinez, D. Felder-Flesch and S. Begin-Colin, Dalton Trans., 2013, 42, 2146-2157.

15 R. Jin, B. Lin, D. Li and H. Ai, Curr. Opin. Pharmacol., 2014, 18C, 18-27.

16 X. Wang, X. Xing, B. Zhang, F. Liu, Y. Cheng and D. Shi, Int. J. Nanomed., 2014, 9, 1601-1615.

17 S. Dolci, V. Ierardi, A. Gradisek, Z. Jaglicic, M. Remskar, T. Apih, M. Cifelli, G. Pampaloni, C. A. Veracini and V. Domenici, Curr. Phys. Chem., 2013, 3, 493-500.

18 H. Gmunder, H. P. Eck and W. Droge, Eur. J. Biochem., 1991, 201, 113-117.

19 S. Dolci, M. Remskar, Z. Jaglicic, F. Pineider, A. Boni, G. Pampaloni, C. A. Veracini and V. Domenici, J. Mater. Sci., 2013, 48, 1283-1291.

20 M. A. Dobrovolskaia and S. E. McNeil, Nat. Nanotechnol., 2007, 2, 469-478.

21 L. G. Delogu, E. Venturelli, R. Manetti, G. A. Pinna, C. Carru, R. Madeddu, L. Murgia, F. Sgarrella, H. Dumortier and A. Bianco, Nanomedicine, 2012, 7, 231-243.

22 M. Pescatori, D. Bedognetti, E. Venturelli, C. Menard-Moyon, C. Bernardini, E. Muresu, A. Piana, G. Maida, R. Manetti, F. Sgarrella, A. Bianco and L. G. Delogu, Biomaterials, 2013, 34, 4395-4403.

23 C. Crescio, M. Orecchioni, C. Menard-Moyon, F. Sgarrella, P. Pippia, R. Manetti, A. Bianco and L. G. Delogu, Nanoscale, 2014, 6, 9599-9603.

24 M. Orecchioni, D. Bedognetti, F. Sgarrella, F. M. Marincola, A. Bianco and L. G. Delogu, J. Transl. Med., 2014, 12, 138.

$25 \mathrm{X}$. Chen, R. Wong, I. Khalidov, A. Y. Wang, J. Leelawattanachai, Y. Wang and M. M. Jin, Biomaterials, 2011, 32, 7651-7661.

26 E. A. Vermeij, M. I. Koenders, M. B. Bennink, L. A. Crowe, L. Maurizi, J. P. Vallee, H. Hofmann, W. B. van den Berg, P. L. van Lent and F. A. van de Loo, PLoS One, 2015, 10, e0126687.

27 R. D. Oude Engberink, E. L. Blezer, E. I. Hoff, S. M. van der Pol, A. van der Toorn, R. M. Dijkhuizen and H. E. de Vries, J. Cereb. Blood Flow Metab., 2008, 28, 841-851.

28 J. Gunn, R. K. Paranji and M. Zhang, Biophys. J., 2009, 97, 2640-2647.

29 A. Beduneau, Z. Ma, C. B. Grotepas, A. Kabanov, B. E. Rabinow, N. Gong, R. L. Mosley, H. Dou, M. D. Boska and H. E. Gendelman, PLoS One, 2009, 4, e4343.

30 A. Gramoun, L. A. Crowe, L. Maurizi, W. Wirth, F. Tobalem, K. Grosdemange, G. Coullerez, F. Eckstein, M. I. Koenders, W. B. van den Berg, H. Hofmann and J. P. Vallee, Arthritis Res. Ther., 2014, 16, R131.

31 A. Barrefelt, M. Saghafian, R. Kuiper, F. Ye, G. Egri, M. Klickermann, T. B. Brismar, P. Aspelin, M. Muhammed,
L. Dahne and M. Hassan, Int. J. Nanomed., 2013, 8, 32413254.

32 L. B. Thomsen, T. Linemann, K. M. Pondman, J. Lichota, K. S. Kim, R. J. Pieters, G. M. Visser and T. Moos, ACS Chem. Neurosci., 2013, 4, 1352-1360.

33 N. Doshi, B. Prabhakarpandian, A. Rea-Ramsey, K. Pant, S. Sundaram and S. Mitragotri, J. Controlled Release, 2010, 146, 196-200.

34 T. Hyeon, S. S. Lee, J. Park, Y. Chung and H. B. Na, J. Am. Chem. Soc., 2001, 123, 12798-12801.

35 D. E. Lee, H. Koo, I. C. Sun, J. H. Ryu, K. Kim and I. C. Kwon, Chem. Soc. Rev., 2012, 41, 2656-2672.

36 C. Sciallero, D. Grishenkov, S. V. Kothapalli, L. Oddo and A. Trucco, J. Acoust. Soc. Am., 2013, 134, 3918-3930.

37 F. Yang, L. Li, Y. Li, Z. Chen, J. Wu and N. Gu, Phys. Med. Biol., 2008, 53, 6129-6141.

38 B. Xu, H. Dou, K. Tao, K. Sun, J. Ding, W. Shi, X. Guo, J. Li, D. Zhang and K. Sun, Langmuir, 2011, 27, 12134-12142.

39 T. Y. Liu, H. H. Huang, Y. J. Chen and Y. J. Chen, Acta Biomater., 2011, 7, 578-584.

40 Y. Sun, Y. Zheng, H. Ran, Y. Zhou, H. Shen, Y. Chen, H. Chen, T. M. Krupka, A. Li, P. Li, Z. Wang and Z. Wang, Biomaterials, 2012, 33, 5854-5864.

41 S. T. Kang and C. K. Yeh, Chang Gung Med. J., 2012, 35, 125139.

42 S. K. Hobbs, W. L. Monsky, F. Yuan, W. G. Roberts, L. Griffith, V. P. Torchilin and R. K. Jain, Proc. Natl. Acad. Sci. U. S. A., 1998, 95, 4607-4612.

43 M. Mehrmohammadi, J. Oh, S. Mallidi and S. Y. Emelianov, Mol. Imaging, 2011, 10, 102-110.

44 N. Singh, G. J. Jenkins, R. Asadi and S. H. Doak, Nano Rev., 2010, 1, 5358.

45 M. Mahmoudi, H. Hofmann, B. Rothen-Rutishauser and A. Petri-Fink, Chem. Rev., 2012, 112, 2323-2338.

46 M. Radu, M. C. Munteanu, S. Petrache, A. I. Serban, D. Dinu, A. Hermenean, C. Sima and A. Dinischiotu, Acta Biochim. Pol., 2010, 57, 355-360.

47 S. Naqvi, M. Samim, M. Abdin, F. J. Ahmed, A. Maitra, C. Prashant and A. K. Dinda, Int. J. Nanomed., 2010, 5, 983-989.

48 C. H. Yeh, J. K. Hsiao, J. L. Wang and F. Sheu, J. Nanopart. Res., 2010, 12, 151-160.

49 A. S. Arbab, G. T. Yocum, H. Kalish, E. K. Jordan, S. A. Anderson, A. Y. Khakoo, E. J. Read and J. A. Frank, Blood, 2004, 104, 1217-1223.

50 G. Tosato and K. D. Jones, Blood, 1990, 75, 1305-1310.

51 K. W. Moore, A. O'Garra, R. de Waal Malefyt, P. Vieira and T. R. Mosmann, Annu. Rev. Immunol., 1993, 11, 165-190. 52 Y. X. Wang, Quant. Imag. Med. Surg., 2011, 1, 35-40.

53 A. Saleh, M. Schroeter, C. Jonkmanns, H. P. Hartung, U. Modder and S. Jander, Brain, 2004, 127, 1670-1677.

54 E. A. Neuwelt, P. Varallyay, A. G. Bago, L. L. Muldoon, G. Nesbit and R. Nixon, Neuropathol. Appl. Neurobiol., 2004, 30, 456-471.

55 C. von Zur Muhlen, D. von Elverfeldt, N. Bassler, I. Neudorfer, B. Steitz, A. Petri-Fink, H. Hofmann, C. Bode and K. Peter, Atherosclerosis, 2007, 193, 102-111. 
56 I. Siglienti, M. Bendszus, C. Kleinschnitz and G. Stoll, J. Neuroimmunol., 2006, 173, 166-173.

57 J. K. Hsiao, H. H. Chu, Y. H. Wang, C. W. Lai, P. T. Chou, S. T. Hsieh, J. L. Wang and H. M. Liu, NMR Biomed., 2008, 21, 820-829.
58 I. Raynal, P. Prigent, S. Peyramaure, A. Najid, C. Rebuzzi and C. Corot, Invest. Radiol., 2004, 39, 56-63.

59 A. S. Arbab, L. A. Bashaw, B. R. Miller, E. K. Jordan, B. K. Lewis, H. Kalish and J. A. Frank, Radiology, 2003, 229, 838-846. 